\title{
Research Paper: Effect of Ankle Brace on the Activity and Co-Contraction of Ankle Muscles During Single-Leg Landing
}

Farnaz Mobini' ${ }^{1}$ Mehrdad Anbarian² ${ }^{2}$, Leila Ghazaleh ${ }^{3 *}$ (D)

1. Department of Physical Education and Sport Sciences, Borujerd Branch, Islamic Azad University, Borujerd, Iran.

2. Department of Sports Biomechanics, Faculty of Sports Sciences, Bu-Ali Sina University, Hamadan, Iran.

3. Department of Sport Physiology, Faculty of Physical Education, Alzahra University, Tehran, Iran.

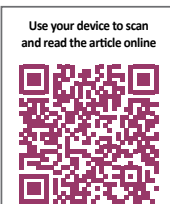

ditation Mobini F, Anbarian M, Ghazaleh L. Effect of Ankle Brace on the Activity and Co-Contraction of Ankle Muscles During Single-Leg landing. Iranian Rehabilitation Journal. 2019; 17(1):17-22. http://dx.doi.org/10.32598/irj.17.1.17

doi http://dx.doi.org/10.32598/irj.17.1.17

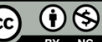

Article info:

Received: 13 Jul 2018

Accepted: 25 Dec 2018

Available Online: 01 Mar 2019

Keywords:

Brace, Electromyography,

Muscle activity, Co-contraction

\section{ABSTRACT}

Objectives: The results of a few studies about the effects of ankle brace on muscles function during the performance of different tasks are contradictory. Moreover, the effect of brace on the co-contraction of ankle muscles is undiscovered. Therefore, the present study investigated the effect of brace usage on the ankle muscles activity and co-contraction during single-leg landing.

Methods: Fifteen non-athletic males aged $22.3 \pm 1.09$ years without any traumatic injury and abnormality of the lower limb participated in this study. Electromyography activity of the ankle muscles (tibialis anterior, lateral gastrocnemius, medial gastrocnemius, peroneus longus and soleus) and muscle co-contraction in the anteroposterior and mediolateral directions were compared between two single-leg landing conditions, in respect of braced and unbraced ankle. The subjects landed from a $60-\mathrm{cm}$ height bench. For the normalization of electromyography amplitudes, maximum voluntary isometric contractions were recorded for each muscle. Paired Samples t-test was used to compare muscle activities and co-contractions between the two conditions of landing.

Results: In general, the activity of selected ankle muscles was reduced in braced condition, compared to the unbraced condition $(\mathrm{P}<0.001)$. This reduction was not significant in the gastrocnemius lateralis muscle. In addition, the muscles co-contraction decreased in both directions during landing in braced condition $(\mathrm{P}<0.05)$.

Discussion: According to the obtained results, ankle brace reduces the activity and cocontraction of ankle joint muscles during landing. These findings can be considered as advantages of using brace, because it could reduce the load imposed on joint and muscles.

\section{* Corresponding Author:}

Leila Ghazaleh, PhD.

Address: Department of Sport Physiology, Faculty of Physical Education, Alzahra University, Tehran, Iran.

Tel: +98 (21) 85692668

E-mail: l.ghazaleh@alzahra.ac.ir 


\section{Highlights}

- Wearing an ankle brace reduces the activity of the ankle joint muscles during landing.

- Wearing an ankle brace reduces the co-contraction of the ankle joint muscles during landing.

\section{Plain Language Summary}

Athletes use braces to protect them from injuries. One of the popular kinds of braces is ankle brace. It is important to know why athletes are greatly satisfied while using an ankle brace. The present study revealed that ankle brace decreases activity and co-contraction of ankle muscles during intense activities like single-leg landing. This finding can be considered an advantage of using an ankle brace because it could reduce the load imposed on joint and muscles.

\section{Introduction}

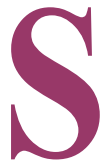

tudies revealed that $15 \%$ of all sports injuries occur in the ankle joint, and $85 \%$ of these injuries are ankle sprains [1]. Moreover, joint stabilization by external protectors can reduce the odds of injury and sprains; thus, therapists recommend athletes to use braces $[2,3]$. Although brace as a supportive tool has been accepted by athletes, researchers are still investigating the mechanism by which brace affects the function of supporting structures of the joint.

In this regard, the mechanism of the bracing effect on the ankle muscles activity has been evaluated. Few researchers have investigated the effect of bracing on the ankle muscles during different tasks [4-7] and reported contradictory results. Hopper and et al. investigated the effect of bracing on the selected muscle activity in netball players in jump landing. They concluded that the electromyographic activity of gastrocnemius and peroneus longus muscles significantly decreased when subjects were braced [7].

Feger et al. determined the effect of bracing on electromyography amplitudes in participants with chronic ankle instability during various tasks. According to their findings, the activity of some ankle muscles reduced during the forward lunge and anterior reach of star excursion balance; while no differences were observed between braced and unbraced conditions during the single limb eyes-closed balance, the posteromedial reach of star excursion balance, or lateral hop exercises [5].

Cardoso et al. indicated that ankle bracing cannot affect the muscles activity during vertical jumping and lateral shuffling [4]. Tesuchida et al. reported the effect of bracing on the activity of selected muscles during landing from $30 \mathrm{~cm}$ and $50 \mathrm{~cm}$ height movements. Their findings suggested that wearing a brace significantly decreased the activity of medial gastrocnemius muscle during landing from a $50 \mathrm{~cm}$ height [6].

Although muscle co-contraction is an important protective mechanism for joints [8], the impact of brace on it has been overlooked by previous researches. Therefore, the present study investigated the effect of brace on the ankle muscles activity and co-contraction in healthy individuals during single-leg landing. Among different tasks, single-leg landing imposes the greatest force on the ankle joint. Thus, this task was considered as an independent variable to determine the effect of ankle brace on muscles function in one of the most difficult dynamic conditions.

\section{Methods}

Fifteen non-athletic male volunteers (Mean \pm SD age: $22.3 \pm 1.09$ years, height: $179.6 \pm 6.64 \mathrm{~cm}$, weight: $74.6 \pm 4.48 \mathrm{~kg}$, and BMI: $23.7 \pm 2.67 \mathrm{kgm}^{2}$ ) were recruited. Inclusion criteria were $\geq 19$ years of age, a normal BMI, not being an athlete. Exclusion criteria were health problems such as traumatic injuries, abnormalities, surgical history, and pain in the lower limb. The Research Council of the Islamic Azad University, Boroujerd Branch, in agreement with the Declaration of Helsinki, approved all the study procedures prior to the onset of study.

For the electromyographic acquisition, Electromyography (EMG) (Biomonitor ME6000 T-16, Finland) was used. Muscle activity was sampled at $1000 \mathrm{~Hz}$ via a 16 bit DAQ-516 A/D card and recorded in a laptop computerizing MegaWin (Mega Electronics Ltd, Kuopio, Finland). The signal-to-noise ratio was set at $110 \mathrm{db}$. 

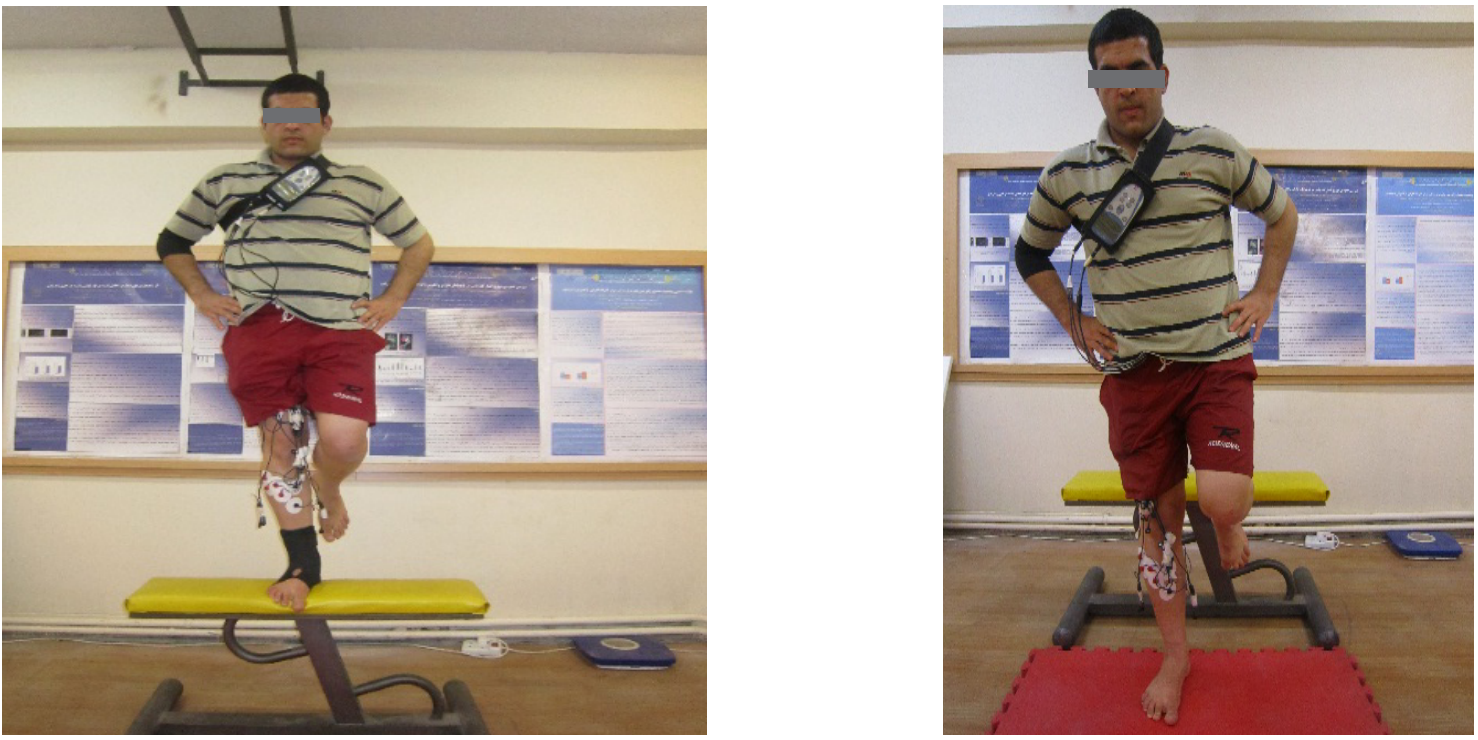

Figure 1. Electrode placement over the ankle muscles and experimental setup with and without a brace

Iranian Rehabilitation Dournal

Pairs of 10-mm diameter $\mathrm{Ag} / \mathrm{Ag} \mathrm{Cl}$ electrodes in dipole array were located on the skin of Tibialis Anterior (TA), Peroneus Longus (PL), Gastrocnemius Lateralis (GL), Gastrocnemius Medialis (GM), and Soleus (S) muscles with an inter-electrode distance of $20 \mathrm{~mm}$ (Figure 1).

For reducing the skin impedance, the skin was shaved and cleaned by alcohol $70 \%$ (ethanol- $\mathrm{C}_{2} \mathrm{H}_{5} \mathrm{OH}$ ) before placing the surface electrodes. The electrodes were fixed at the abdominal muscles according to the European concerted action Surface EMG for a Non-Invasive Assessment of Muscles (SENIAM) [9]. The right leg was randomly selected for the placement of electrodes. After electrode placement and warm-up, at trials, three Maximum Voluntary Isometric Contractions (MVIC) were recorded for each muscle to normalize SEMG amplitudes. Every participant was trained to perform 2 second maximum contraction against the resistance. The resisted movements were as follows: dorsiflexion-tibialis anterior, pronation-peroneus longus, plantarflexion-medial and lateral gastrocnemius and soleus $[9,10]$.

The participant sat on a bench while performing the MVICs in respect of tibialis anterior and the peroneal muscles. In the gastrocnemius and soleus MVICs, to ensure that the participant would not slide backward during the contraction, the participant sat on the floor with their back against a wall. Three consecutive maximum efforts were separated by a $1 \mathrm{~min}$ recovery period to avoid fatigue. For calculating average Root Mean Square (RMS) from three trials, a $600 \mathrm{~ms}$ window in the middle of the $2 \mathrm{~s}$ recording period was applied. After performing the normalization test, the electrical activity of the muscles was recorded while performing single-leg landing tests on a $60-\mathrm{cm}$ height bench both unbraced and braced (ankle brace) (Figure 1). This study used the ankle support brace by an elastic strap (model 1009).

Three balanced single-leg landing in each condition (braced and unbraced) were recorded for every participant. Muscle activity was considered from the moment of landing to one second after landing. The moment of landing was determined by a single electrical footswitch. To measure the amount of muscles electrical activity, the average root mean square of every three trial was computed and normalized while considering corresponding MVIC trials for each muscle.

To reduce electrical interferences from external sources, the signals were filtered by a bandwidth Butterworth fourth-order filter of 10-500 Hz and a band-stop filter of $50 \mathrm{~Hz}$. The Co-Contraction Index (CCI) [11] was used to represent ankle-dorsiflexor and extensor (TA and GL), and ankle invertor and evertor (TA and PL) muscles cocontraction.

$$
C C I=2 \times \frac{E M G_{A N T}}{E M G_{A G}+E M G_{A N T}} \times 100
$$

To measure the CCI, the antagonistic muscle activity (the average of root mean square) was divided by the mean score of agonistic $\left(\mathrm{EMG}_{\mathrm{AG}}\right)$ and antagonistic (EM$\left.\mathrm{G}_{\mathrm{ANT}}\right)$ muscles activations.

The average RMS values of the co-contractions and muscles activities between the two conditions of landing were compared using the paired samples t-test. Statisti- 
cal analysis was carried out using SPSS and $\mathrm{P}<0.05$ was considered as statistically significant.

\section{Results}

As shown in Figure 2, brace reduces the activity of all selected ankle muscles. This decrease in muscle activity was statistically significant except for the GL $(\mathrm{P}<0.001)$. In general, brace usage reduced the average activity of selected muscles by $15.82 \%$, which was statistically significant $(\mathrm{P}<0.001)$ (Table 1).

The results of the effect of brace on the ankle muscles co-contraction are presented in Figure 3. These results suggested that using brace reduces the co-contraction rate of ankle muscles $(\mathrm{P}<0.05)$ in anteroposterior (plantarflexor and dorsiflexor muscles), and mediolateral (evertor and invertor muscles) directions.

\section{Discussion}

The obtained results suggested that using brace decreased the ankle muscles activity, in general. The results of some studies are in-line with the current research $[5,7]$; while others [4] are inconsistent with the present study. The reduced ankle muscle activity by a brace, can be associated with two other effects of brace on the joint. Previous studies have argued that brace controls the joint range of motion [12]. By controlling the joint's range of motion, the brace can partly reduce the amount of load imposed on the joint muscles, thereby reducing muscle activity [13]. Additionally, brace increases the joint's mechanical stability [14]. By increasing the passive mechanical stability, the brace reduces the need for the active mechanical stability of the joint caused by muscle intervention. Reducing muscle intervention in stabilizing the joint leads to decreased muscles activity.

The most important finding of the present study was reduced ankle muscle co-contraction, both in the plantarflexors and dorsiflexors muscles as well as evertor and invertor muscles after using a brace. Based on the literature review, this issue has not been assessed in previous studies. Co-contraction is among the functional mechanisms of agonist/antagonistic muscles to increase joint stability during motion performance [8]. However, because the brace produces passive stability in the joint, [15] the requirement of active stability for the joint will reduce. It can be considered as a benefit of using brace; as active stability derived from co-contraction has the potential to increase the compressive forces within the joint [16].

The selection of the right leg for the experiment without paying attention to the dominant and non-dominant

Table 1. Percent reduction in ankle muscle activity due to the use of brace during single-leg landing

\begin{tabular}{ccccccc}
\hline Percent Reduction & TA & PL & GL & GM & S & Total \\
\hline \multirow{2}{*}{ Mean \pm SD } & $22.00 \pm 16.57$ & $17.57 \pm 9.76$ & $7.45 \pm 33.22$ & $19.86 \pm 11.3$ & $13.65 \pm 13.83$ & $15.82 \pm 9.75$ \\
\hline
\end{tabular}

Iranian Rehabilitation Journal

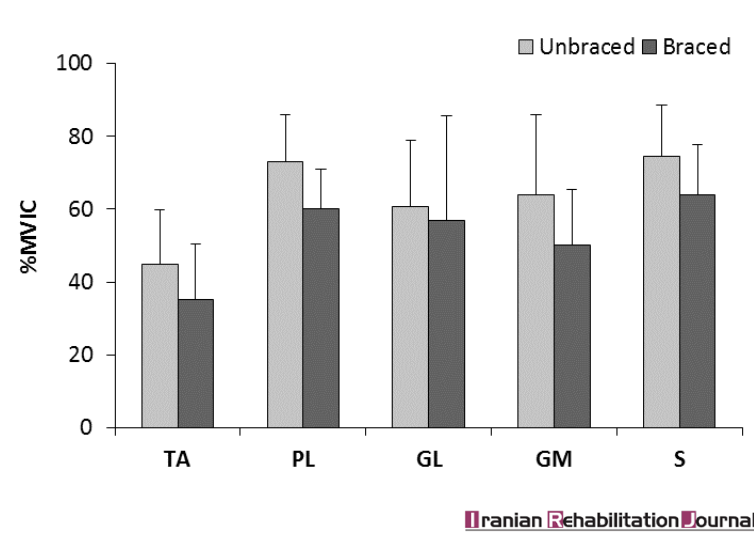

Figure 2. Mean \pm SD scores of ankle muscles activity during two single-leg landing conditions

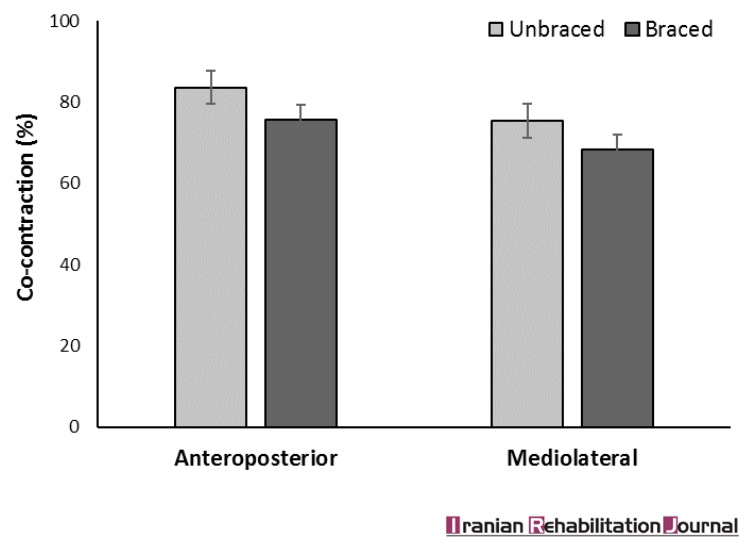

Figure 3. Percentage of the anteroposterior and mediolateral ankle muscles co-contraction during two single-leg landing conditions 
leg was a limitation to this study and it is recommended for consideration in future studies.

\section{Conclusion}

According to the present study, using ankle brace reduced the ankle muscles activity and co-contraction. It can be speculated as a functional mechanism of the brace; thus, such use of brace is recommended for athletic rehabilitation procedures.

\section{Ethical Considerations}

\section{Compliance with ethical guidelines}

The Research Council of the Islamic Azad University, Boroujerd Branch, in agreement with the Declaration of Helsinki, approved all the study procedures prior to the onset of study.

\section{Funding}

This research did not receive any specific grant from funding agencies in the public, commercial, or not-forprofit sectors.

\section{Authors contributions}

Study concept and design: Farnaz Mobini, Mehrdad Anbarian; Data collection: Farnaz Mobini, Leila Ghazaleh; Interpretation of data: Mehrdad Anbarian; Supervision: Mehrdad Anbarian; and Writing-review and editing: Leila Ghazaleh, Mehrdad Anbarian.

\section{Conflict of interest}

The authors declare no conflict of interest.

\section{References}

[1] Balduini F, Tetzlaff J. Historical perspectives on injuries of the ligaments of the ankle. Clinical Sports Medicine. 1982; 1(1):3-12. [PMID]

[2] Kemler E, van de Port I, Backx F, van Dijk CN. A systematic review on the treatment of acute ankle sprain. Sports Medicine. 2011; 41(3):185-97. [DOI:10.2165/11584370-00000000000000] [PMID]

[3] Barlow G, Donovan L, Hart JM, Hertel J. Effect of lace-up ankle braces on electromyography measures during walking in adults with chronic ankle instability. Physical Therapy in Sport. 2015; 16(1):16-21. [DOI:10.1016/j.ptsp.2014.02.002] [PMID]
[4] Cardoso JR, Guerino CD, Santos MB, Mustafá TA, Lopes AR, Paula MC. Use of ankle bracing for volleyball activities. Revista Brasileira de Medicina do Esporte. 2005; 11(5):276-80. [DOI:10.1590/S1517-86922005000500006]

[5] Feger MA, Donovan L, Hart JM, Hertel J. Effect of ankle braces on lower extremity muscle activation during functional exercises in participants with chronic ankle instability. International Journal of Sports Physical Therapy. 2014; 9(4):47687. [PMID] [PMCID]

[6] Tsuchida Y, Miyakawa T. Effects of ankle braces on ground reaction force and electromyography during landing movement. Kawasaki Journal of Medical Welfare. 2013; 19(1):13-6.

[7] Hopper DM, McNair P, Elliott BC. Landing in netball: Effects of taping and bracing the ankle. British Journal of Sports Medicine. 1999; 33(6):409-13. [DOI:10.1136/bjsm.33.6.409] [PMID] [PMCID]

[8] Darainy M, Ostry DJ. Muscle cocontraction following dynamics learning. Experimental Brain Research. 2008; 190(2):153-63. [DOI:10.1007/s00221-008-1457-y] [PMID]

[9] Hermens HJ, Freriks B, Disselhorst-Klug C, Rau G. Development of recommendations for SEMG sensors and sensor placement procedures. Journal of Electromyography and Kinesiology. 2000; 10(5):361-74. [DOI:10.1016/S10506411(00)00027-4]

[10] Murley GS, Menz HB, Landorf KB. Foot posture influences the electromyographic activity of selected lower limb muscles during gait. Journal of Foot and Ankle Research. 2009; 2:35. [DOI:10.1186/1757-1146-2-35] [PMID] [PMCID]

[11] Ervilha UF, Graven-Nielsen T, Duarte M. A simple test of muscle coactivation estimation using electromyography. Brazilian Journal of Medical and Biological Research. 2012 45(10):977-81. [DOI:10.1590/S0100-879X2012007500092] [PMID] [PMCID]

[12] Eils E, Rosenbaum D. The main function of ankle braces is to control the joint position before landing. Foot \& Ankle International. 2003; 24(3):263-8. [DOI:10.1177/1071100703024 00312] [PMID]

[13] Earl JE, Piazza SJ, Hertel J. The protonics knee brace unloads the quadriceps muscles in healthy subjects. Journal of Athletic Training. 2004; 39(1):44-9. [PMID] [PMCID]

[14] Kamiya T, Kura H, Suzuki D, Uchiyama E, Fujimiya M, Yamashita T. Mechanical stability of the subtalar joint after lateral ligament sectioning and ankle brace application: A biomechanical experimental study. American Journal of Sports Medicine. 2009; 37(12):2451-8. [DOI:10.1177/0363546509339578] [PMID]

[15] Eils E, Imberge S, Völker K, Rosenbaum D. Passive stability characteristics of ankle braces and tape in simulated barefoot and shod conditions. American Journal of Sports Medicine. 2007; 35(2):282-7. [DOI:10.1177/0363546506294471] [PMID]

[16] Hodge W, Fijan R, Carlson K, Burgess R, Harris W, Mann R. Contact pressures in the human hip joint measured in vivo. Proceedings of the National Academy of Sciences of the United States of America. 1986; 83(9):2879-83. [DOI:10.1073/ pnas.83.9.2879] [PMID] [PMCID] 
This Page Intentionally Left Blank 